\title{
A Study on Granular Formulation of Sodium Pentachlorophenate for Particle Board
}

\author{
APARNA KALAWATE ${ }^{1,2^{*}}$ and K.Ch. VARADARAJULU ${ }^{1}$ \\ ${ }^{1}$ Indian Plywood Industries Research \& Training Institute, Bangalore, India \\ ${ }^{2}$ Zoological Survey of India, Western Regional Centre, Pune, India \\ aparna_ent@yahoo.co.in
}

Received 17 November 2015 / Revised 1 February 2016 / Accepted 26 February 2016

\begin{abstract}
Sodium pentachlorophenate (NaPCP)(Biocel-WP) was evaluated against wood destroying fungus. $\mathrm{NaPCP}$ was evaluated at 0.25 and $0.5 \%$ concentration on the weight of liquid resin taken for the experiment. The chemical was incorporated in the glue/adhesive composition. The particles were blended with the glue. Control panels were also made without chemical incorporation in the glue. The treated and control samples were exposed against the wood destroying fungus for three months to test the efficacy of NaPCP. From the results of the study it was found that NaPCP at $0.5 \%$ resisted the attack of wood destroying fungus. The treated and untreated samples were also subjected to assess physical and mechanical properties as per relevant standard. The tested panels conformed to the physical and mechanical properties.
\end{abstract}

Keywords: Particle board, Granular formulation, Sodium pentachlorophenate

\section{Introduction}

The primary objective of the preservative treatment of wood is to increase the life of the material in service, thus decreasing the ultimate cost of the product and avoiding the need for frequent replacements. Life of treated wood is considerably greater than that of the untreated material. The increase in service life of timber by the application of appropriate preservatives has significant effect in the field of wood utilization. Preservative treatment of short rotation non-durable timber has not only increased the supply of timber available for different purposes but has also brought about certain other benefits. In addition, preservation contributes to the reduction of the demand for replacing wood, thus conserving the forests.

The wood rotting fungi particularly basidiomycetes damage forest wood even more than insects. These basidiomycetes are categorized as either white rot fungi (WRF) or brown rot fungi (BRF) ${ }^{1}$. Among these two, WRF degrade all major components of wood i.e. cellulose, hemicellulose and lignin by secretion of cellulolytic and lignolytic enzymes. The fungi that grow on wood and decay it are called as lignicolous fungi. Many species of primitive plants, known as fungi, live in wood. Some of these organisms use only the food that is stored in the wood (molds and sap stains), while others (wood-destroying fungi) attack the cellulose or lignin and ultimately rot the wood. Under suitable conditions these wood-destroying 
organisms may attack both trees and manufactured wood products. These specialized plants attack the structural elements and cause deterioration of wood (decay or rot), thus degrading its natural properties.

Compounds of pentachlorophenol $\left(\mathrm{C}_{8} \mathrm{Cl}_{5} \mathrm{OH}\right)$ and particularly the sodium salt have been widely used for a variety of agricultural and industrial purposes as a wood preservative, termite deterrent. Though the sodium salt of pentachlorophenate (Na-PCP) is a proven fungicide, it has been recognized as an irritating substance to the skin, eyes and the mucous membrane of nose, mouth and pharynx. All these problems are not associated with Biocel WD a brand name given to NaPCP because of its granular nature as claimed by the manufacturer (M/s Excel Industries Pvt. Ltd.). In an accelerated laboratory evaluation, rubber wood treated with borax and/or in combination with NaPCP $(0.5 \%)$ can provide protection against white rot fungi ${ }^{2}$. The old formulation of NaPCP was in powder form which was causing irritation to the mucous membrane. Recently, M/s Excel Industries Pvt. Ltd. has come up with granular formulation of NaPCP which may not cause any hazards. Hence, the granular product will be useful for the industry especially the workers who work with this chemical. The present study dealt with the evaluation of bioefficacy of Sodium Pentachlorophenateagainst wood decay fungus.

\section{Experimental}

Urea formaldehyde (UF) resin was used in this study.

\section{Manufacture of PB}

\section{Glue Bending}

The poplar particles were used in this study for making PB. The particles were dried to a moisture content of $6-8 \%$. The dried particles were mixed with UF resin, admixed with NaPCPat 0.25 and $0.5 \%$ concentration on the weight of liquid resin respectively. Wax emulsion and hardener was also added to resin and mixed completely about 20-30 minutes. The resin was blended with the poplar particles manually.

\section{Mat formation}

The glue blended particles were placed into a mat forming box with base dimensions of $330 \mathrm{~mm} \times 330 \mathrm{~mm}$. Aluminium/ SS plates spreaded with releasing agents were placed on either sides of the mat furnish. Prepressing and compression of the particles were done by pressing a matching wooden plate on the particle mat in the box by applying manual pressure. Supporting rods to control the thickness to $12 \mathrm{~mm}$ were placed on either ends of the assembly.

\section{Hot pressing}

The assembly was then loaded into a hot press of size $350 \mathrm{~mm} \times 350 \mathrm{~mm}$ wherein temperature of the platens was maintained at $155-160{ }^{\circ} \mathrm{C}$. Pressure of $25 \mathrm{~kg} / \mathrm{sq} \mathrm{cm}$ for compression cycle and $12 \mathrm{~kg} / \mathrm{sq} \mathrm{cm}$ for curing cycle with requisite curing time were employed.

Initially the pressure is given higher so as to create a high surface density of the particle board. The core density was then formed by reducing the applied pressure to $12-16 \mathrm{~kg} / \mathrm{sq} \mathrm{cm}$. After stipulated period the pressure was brought down to zero for few seconds to release the generated steam and gases from the particle boards. Then the press was completely opened to download the boards. The boards were kept for stabilization for about 24-48 hours to attain equilibrium moisture content and then trimmed. The trimmed boards were further dimensioned to required sizes and subjected for further testing. 


\section{Physico-mechanical test}

The trimmed boards were further dimensioned to required sizes and subjected for testing as per IS:3087- Specification for Medium Density Particle Boards ${ }^{3}$. The results are given in Table 1.

Table 1. Physico-mechanical properties of particle board as per IS:3087 (2005)

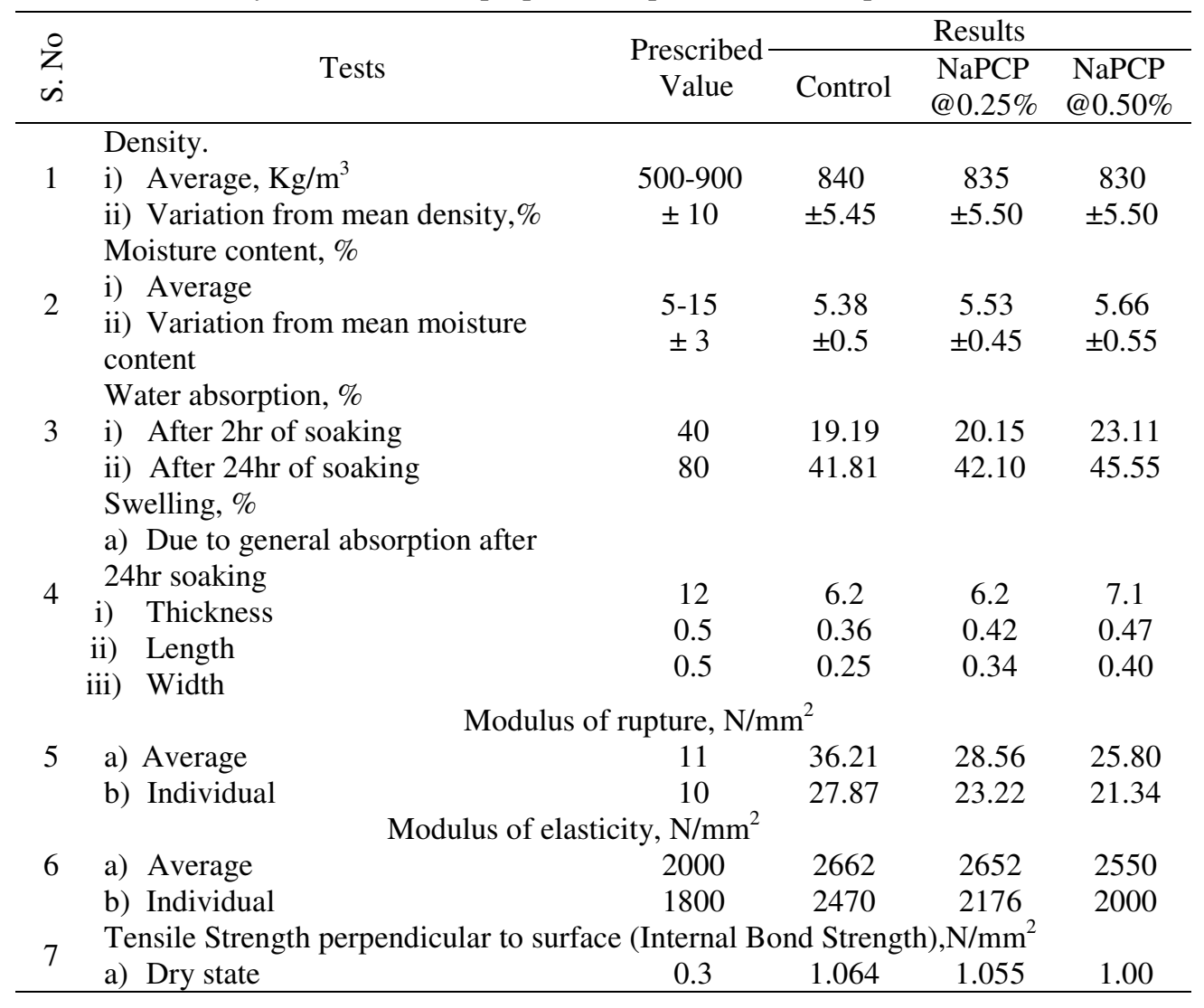

\section{Efficacy evaluation}

\section{White rot (Agar block method)}

A nutrient medium containing $20 \mathrm{~g}$ of agar and $20 \mathrm{~g}$ of malt extract in a litre of distilled water, autoclaved at $120{ }^{\circ} \mathrm{C}$ for 20 minutes was taken in Kolle flask. The test blocks were made of the size $50 \mathrm{~mm} \times 25 \mathrm{~mm} \times 15 \mathrm{~mm}$. The treated MDF and along with untreated control samples in six replicates were studied against white rot fungus (Polyporousversicolor). The whole set of flasks were kept at room temperature $\left(25 \pm 5{ }^{\circ} \mathrm{C}\right)$ and $60-70 \%$ relative humidity for 12 weeks. The test was carried out as per IS: 4873 (Anonymous, 2008). After the completion of 12 weeks, the samples were removed from the kolle flask autoclaved and the mycelium adhering to it was cleaned by taking care not to remove the splinters of the samples. The blocks were dried in an oven to a constant weight. The mean percentage weight loss was determined using following equation:

$$
\% \text { weight loss }=\left[\left(\mathrm{W}_{\mathrm{o}}-\mathrm{W}_{1}\right) / \mathrm{W}_{\mathrm{o}}\right] \times 100
$$


Where $\mathrm{W}_{\mathrm{o}}$ is oven dry weight of sample prior to exposure and $\mathrm{W}_{1}$ is the oven dry weight of samples after exposure to fungus.

\section{Mould fungi}

The toxicity test was carried out according to Padmanabhan et al ${ }^{4}$. Treated MDF and untreated samples were utilized to study the bioefficacy against mould fungi. The specimen of size $12.5 \mathrm{~cm} \times 12.5 \mathrm{~cm}$ was prepared. The moisture content of the sample was brought to $30 \%$ by dipping the samples in water for mould fungi study. All these samples in the lot of six replicates were exposed against mould fungi. The control samples were dipped in water. The water (control) and chemical treated samples were sprayed with a suspension of different moulds viz. Aspergillus spp. Penicilliumspp and Verticillium spp. These samples were kept in incubation chamber (to maintain relative humidity of $70 \pm 5 \%$ and temperature of $25 \pm 5{ }^{\circ} \mathrm{C}$ ) for a period of 6 weeks. After 6 weeks of incubation, test samples were removed and thepercentage of deterioration was observed and recorded.

\section{Results and Discussion}

The average actual density of Particle board was 835 and $830 \mathrm{~kg} / \mathrm{m}^{3}$ in case of NaPCP @ 0.25 and $0.5 \%$ concentration respectively (Table 1 ). The targeted density was $900 \mathrm{~kg} / \mathrm{m}^{3}$. The prescribed average moisture content is $5-15 \%$ at $\pm 3 \%$ variation from mean moisture content as per IS: $3087^{3}$. The average moisture content calculated for the PB samples treated with NaPCP at 0.25 and $0.5 \%$ concentration was 5.53 and $5.66 \%$ respectively. The control samples recorded the moisture content of $5.38 \%$. The treated samples have recorded a bit increase in moisture content as compare to control. This may be due to the wood preservative chemical i.e. NaPCP incorporation in the sample.

The effect of moisture absorption by PB is swelling in the thickness. The addition of $\mathrm{NaPCP}$ has less effect on the water absorption and swelling. The water absorption by PB treated with NaPCPat $0.25 \%$ concentration was 20.15 and $42.10 \%$ after 2 and 24 hours of soaking respectively. While, the water absorption at $0.5 \%$ was 23.11 and $45.55 \%$ after 2 and 24 hours of soaking respectively. Though the water absorption for the treated samples were higher than the untreated, but felled within the prescribed limit as per the relevant standard for medium density particle board. The thickness swelling was 6.02 and 7.1 at 0.25 and $0.5 \%$ concentration respectively due to general absorption after 24 hours. The length was increases by 0.42 and $0.47 \%$ at $0.25 \%$ concentration of the biocide. The average Modulus of Elasticity (MoE) was 2652 and $2550 \mathrm{~N} / \mathrm{mm}^{2}$ for 0.25 and $0.5 \%$ concentration respectively. The control Boards recorded $2662 \mathrm{~N} / \mathrm{mm}^{2}$. The average Modulus of Rupture (MoR) was observed as 28.56 and $25.80 \mathrm{~N} / \mathrm{mm}^{2}$ at 0.25 and $0.5 \%$ concentration respectively against untreated control $\left(36.21 \mathrm{~N} / \mathrm{mm}^{2}\right)$.Tensile strength perpendicular to surface (Internal bond strength) was 1.055 and $1.00 \mathrm{~N} / \mathrm{mm}^{2}$ for 0.25 and $0.5 \%$ concentration respectively. From the physic-mechanical studies it can be seen that NaPCP treated samples conformed to the tested physico-mechanical properties as per $3087^{3}$.

The treated and untreated samples were exposed against white rot in the kolle flask. The test was performed as per IS: $4873^{5}$. The samples were kept in kolle flask for three months. After the completion of three months the samples were removed and the percentage of weight loss was calculated. The Average percentage of weight loss of $0.19 \%$ in the PB samples treated with NaPCP at $0.25 \%$ concentration was found. The PB samples treated with $\mathrm{NaPCP}$ at $0.5 \%$ concentration recorded $0.14 \%$ average percent weight loss against 97.5\% weight loss in control samples (Table 2). The average weight loss in NaPCP at $0.25 \%$ 
was at par with $0.5 \%$ concentration treated samples. These results clearly show that the formulation prepared by M/s Excel India Pvt. Ltd. has proved excellent protection to PB samples against White rot fungus.

Table 2. Efficacy of Biocel-WD against White rot (PB)

\begin{tabular}{cc}
\hline Chemical concentration, $\%$ & Mean percent weight loss \\
\hline 0.25 & $0.19(0.054)$ \\
0.5 & $0.14(0.061)$ \\
Control & $97.5(0.040)$ \\
\hline
\end{tabular}

*Mean of six samples, "Values in parenthesis are standard deviation

Results for the exposure study of NaPCP treated samples against mould are presented in Table 3. The NaPC Ptreated and untreated samples were exposed against mould fungi. After completion of exposure study, the samples were removed from the incubation chamber and observed for the surface area covered by the mould fungi. NaPCP proved as best mouldicide at both the tested concentration. The treated PB samples were free from the attack of mould fungi. The untreated control samples were completely covered with the mould growth.

Table 3. Efficacy of Biocel-WD against Mould Fungi (PB)

\begin{tabular}{cc}
\hline Chemical concentration, \% & Mean percent surface attack ${ }^{*}$ \\
\hline 0.25 & 00 \\
0.5 & 00 \\
Control & 100 \\
\hline \multicolumn{3}{c}{ "Mean of six samples }
\end{tabular}

\section{Conclusion}

$\mathrm{NaPCP}$ was tested for its efficacy against wood destroying fungus. The method adopted to test the efficacy was as per IS: $4873^{2}$ for white rot fungi. The PB was treated by addition of the preservative chemical in the glue. The treated and untreated control samples of PB were exposed to wood destroying fungus for a period of three months. From the experimental findings the following conclusion can be drawn:

1. NaPCPat $0.5 \%$ on the weight of liquid resin has completely protected the MDF against wood degrading fungus.

2. NaPCP has not hampered the glue adhesion strength of the boards.

3. The new formulation developed by M/s. Excel Industries Ltd., Mumbai, is not irritant to the mucous membrane because of its granular nature as claimed by Manufacturer. Hence, NaPCP (Biocel-WD) is not noxious as compared to the powder formulation of $\mathrm{NaPCP}$.

\section{References}

1. Anonymous, IS: 3087, Specification for Medium Density Particle Boards.Bureau of Indian Standards, New Delhi, 2005.

2. Anonymous, IS: 4873 Part 1 . Methods of laboratory testing of wood preservatives against fungi and borers (powder post beetles) determination of threshold values of wood preservatives against fungi (second revision), Bureau of Indian Standards, New Delhi, 2008.

3. Balasundaran M and Gnanaharan R, J Trop Forest Sci., 1990, 2(4) 303-306. 
4. Padmanabhan S, Kamal S Z M and Ananthanarayan S, (1997). Development of protective measures for wood and wood based panels using B.M.-59: A new boron based chemical, IPIRTI Research report No. 99, 55.

5. Rauel K and Barnoud F, Degradation of wood by microorganisms, In: T. Higuchi (Eds.), Biosynthesis and Biodegradation of wood components, Academic Press Inc. Florida, 1985, 441. 